\title{
Anti-inflammatory and Anti-arthritic Activity of Rosmarinic acid Isolated from Rosmarinus officinalis in an Experimental Model of Arthritis
}

\author{
Tianhu Wei', Yuan Liu ${ }^{2}$, Meirong $\mathrm{Li}^{3, *}$ \\ 1Department of Bao's Orthopedic, Inner Mongolia International Mongolian Hospital, Hohhot City, Inner Mongolia, CHINA. \\ ${ }^{2}$ Department of Emergency, The First Affiliated Hospital of Zhengzhou University, 1 Jianshe Road, Zhengzhou City, Henan, CHINA. \\ ${ }^{3}$ Department of Rheumatology, XuZhou Central Hospital, XuZhoucity, JiangSu Province, CHINA.
}

\begin{abstract}
Background: Rosmarinus officinalis L. (family Lamiaceae is a perennial herb or small woody evergreen tree, commonly known as rosemary, which is native to the Mediterranean and Asia and reasonably hardy in cool climates. It has been used as a decoction in traditional Unani and Swedish medicine for the treatment of inflammatory diseases. Aim: To isolate rosmarinic acid (RA) from $R$. officinalis. leaf extract and to evaluate its protective effects against Freund's adjuvant-induced arthritis in rats. Materials and Methods: Arthritis was induced via sub-plantar injection of $1 \mathrm{mg}$ heat-killed Mycobacterium tuberculosis (complete Freund's adjuvant, CFA) into the left hind paw of rats. The experiment was designed and optimized based on published methods. Results: At $60 \mathrm{mg} / \mathrm{kg}$, the RA fraction of the methanolic extract of $R$. officinalis L. exerted potentially effective anti-arthritic effects by controlling inflammation in an adjuvant-induced experimental model. Conclusion: Considering experimental findings relating to pharmacological and biochemical parameters, we conclude that oral administration of the RA fraction ( 30 and $60 \mathrm{mg} / \mathrm{kg}$ ) from the methanolic extract of $R$. officinalis L. exerts anti-arthritic effects and controls inflammation in an adjuvant-induced arthritis rat model. RA is therefore a promising plant-derived anti-arthritic agent for the treatment of inflammatory disorders.
\end{abstract}

Key words: Freund's adjuvant-induced arthritis, Rosmarinic acid, Rosmarinus officinalis L., Histopathology, Inflammation.

\section{INTRODUCTION}

Rheumatoid join pain is a musculoskeletal disorder (MSD) long-experienced by Homo sapiens. ${ }^{1}$ It is notable amongst common inflammatory conditions and is described by the changes in synovial linings of diarthrodial joints, which prompts forceful ligament movement and dynamic hard frictions if remain untreated, rheumatoid joint inflammation regularly prompts dynamic joint demolition. ${ }^{2}$ It is a provocative condition that occurs regularly in middle age, (40-50) and 50\% of patients endure the condition with irregularities in daily working due to the persistent aggravation of peripheral joints. ${ }^{3}$ The chronic nature of the disease means that many older patients require an analgesic treatment regimen. Drugs currently available for the treatment of rheumatoid arthritis include immunosuppressant and antiinflammatory therapies, such as methotrexate and diclofenac sodium with severe side effects and demage. Herbal drugs present advantages over allopathic medications and should be considered in the treatment of arthritis. ${ }^{4}$ A number of herbal plants have previously been found to be effective in preclinical rodent models of arthritis. ${ }^{4,5}$ Such activities are related to the presence of various chemical constituents in plants.

The present study aimed to isolate the main active constituent (rosmarinic acid; RA)
Submission Date: 01-08-2020; Revision Date: 15-12-2020; Accepted Date: 30-01-2021

DOI: 10.5530/ijper.55.2.89 Correspondence: Dr. Meirong Li Department of Rheumatology, XuZhou Central Hospital, XuZhoucity, JiangSu Province, CHINA. Phone no: +86-18710853410

Email id: limeirong1200@ sina.com

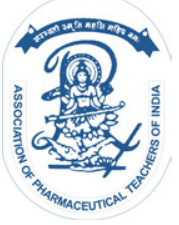

www.ijper.org 
from Rosmarinus officinalis L. and evaluate its activity against rheumatoid arthritis in rats. The other main constituents present in $\mathrm{R}$ officinalis $\mathrm{L}$. are 1,8-cineole, alpha pinene, camphor, borneol, camphene, limonene, linalool, terpineol, verbenol, apigenin, diosmeti, diosmin, oleanolic acid, and ursolic acid. ${ }^{6,7}$ The efficacy of some of these agents in the treatment of arthritis has been shown previously; this study was designed to evaluate the effect of RA, an anti-inflammatory agent, against arthritis. Novel medications, such as tumor necrosis factor (TNF) inhibitors and other new drugs, may be beneficial for the treatment of patients with rheumatoid arthritis. TNF- $\alpha$ level in CFA-treated rats were also determined by authors to access TNF- $\alpha$ level inhibition or modulation. This study were aimed to provide a better cure in patients of Rheumatoid arthritis and help researchers to explore its molecular mechanism in clinical studies

\section{MATERIALS AND METHODS}

\section{Drugs and chemicals}

Methotrexate was obtained as an API sample (B. No. MT 45612) from Sun Pharmaceuticals Pvt. Ltd., (H. P), India. Fluid adjuvant (CFA) (SLBK1731V) and RA $(97.9 \%$, RMA1478N) were obtained from Sigma- Aldrich Chemical Co. (St Louis, MO, USA). Different enzymes diagnostic kits like Aspartate transaminase (AST), alanine transaminase (ALT), and alkaline phosphatase (ALP) were purchased from Qingdao Hihealth Medical Technology Co., Ltd. China. Any other chemicals and solvents utilized were of analytical grade.

\section{Animals}

Experiments were performed using healthy (6-8 weeks) Wistar rats of both sexes. The animals were housed in polypropylene pens. Paddy husk was given as bedding material and was changed every day. The cages were maintained neat and clean. Six rats were kept in each cage and were given a standard pellet diet and water ad libitum. Rats were kept in an inside and out ventilated room, under $12 \mathrm{hr}$ light-dark cycles. Room temperature was maintained up at $22-24^{\circ} \mathrm{C}$. All protocols were confirmed and performed as per animal ethical guidelines for experimentation on animals (IEC/2018/05).

\section{Collection and authentication of plant material}

R. officinalis L. leaves were gathered between November and December, 2019, frozen and freeze-dried from an herbal garden of Shandong, China (36.6192686689454, 117.47036191534195), in the month of July 2019. The plant material was identified, authenticated and kept for specifications (V. no. Consult/2019/2424-09).

\section{Preparation of $\boldsymbol{R}$. officinalis L. extract}

Air-dried powdered R. officinalis L. leaves (500 g) were extracted using methanol. After extraction, excess methanol was removed using a rotary evaporator, the extract was preserved in an airtight container and refrigerated. The extract was used to estimate total polyphenol, flavonoid and RA contents.

\section{Chemical characterization}

\section{Phytochemical screening of the methanolic extract of R. officinalis (MERO)}

Phytochemical in plant extracts were screened using the methods described by Kokate et al. ${ }^{8}$ and is listed in Table 1 .

\section{Total phenol content ditermination}

Total phenolic contents of extract from R. officinalis were determined using the Folin-Ciocalteu method. ${ }^{9}$ The absorbance was measured using a double-beam ultraviolet/ visible (UV/Vis) spectrophotometer (EI model no. 5772, Shumadzu, Japan) and compared to that of the blank. The total phenol content (as pyrogallol equivalents) was calculated from the calibration curve.

\section{Total flavonoid content determination}

An aluminum chloride colorimetric method was used to estimate the flavonoids content. ${ }^{10}$ An aliquot of the RA portion $(0.5 \mathrm{~mL})$ was mixed with $1.5 \mathrm{~mL}$ methanol, $0.1 \mathrm{~mL} \mathrm{10 \%}$ aluminum chloride, $0.1 \mathrm{~mL} 1 \mathrm{M}$ potassium acetic acid derivation and $2.8 \mathrm{~mL}$ distilled water. The response continued at $25^{\circ} \mathrm{C}$ (room temperature) for 30 min and the absorbance was subsequently estimated at $415 \mathrm{~nm}$. A calibration curve was plotted subsequent to estimating the absorbance of quercetin standard solutions at concentrations ranging from 10 to 70 ppm in methanol. Flavonoids were measured from the quercetin standard curve. ${ }^{11}$

\section{Extraction and isolation of $R A$}

A $5 \mathrm{mg}$ sample of extract was washed with $80 \mathrm{~mL}$ $\mathrm{n}$-hexane for $10 \mathrm{~h}$ to remove fat content and refluxed

\begin{tabular}{|c|c|c|}
\hline \multicolumn{3}{|c|}{ Table 1: Phytochemical Screening of RA. } \\
\hline S.no. & Test & Present (+) / Absent (-) \\
\hline 1. & Alkaloids & + \\
\hline 2. & Flavonoids & + \\
\hline 3. & $\begin{array}{c}\text { Tannins and Phenolic } \\
\text { compounds }\end{array}$ & + \\
\hline 4. & Glycosides & + \\
\hline 5. & Steroids & - \\
\hline 6. & Carbohydrates & - \\
\hline 7. & Protiens & + \\
\hline
\end{tabular}


with 1:1, $\mathrm{H}_{2} \mathrm{O}$ : ethanol twice for $10 \mathrm{~h}$. The sample was then extracted and isolated as per method used by Akoury et al. ${ }^{12}$ with slight modifications. A high yield (88\%) of aqueous RA extract was obtained via Soxhlet extraction under optimal conditions.

\section{Identification of $R A$}

\section{Preparation of stock solution}

Ten milligrams of RA (standard and test) were mixed with $5 \mathrm{~mL}$ dimethyl sulfoxide (DMSO) diluted with $20 \mathrm{~mL}$ methanol and separated through Whatman filter paper to obtain a $500 \mu \mathrm{g} / \mathrm{mL}$ RA solution.

\section{Thin layer chromatography (TLC) high performance liquid chromatography (HPLC), and infrared spectroscopy (IR) of the RA fraction}

The TLC method, described in the VIII Portuguese Pharmacopeia, was employed, with slight modifications. Briefly, separation was performed using commercially produced silica gel chromatographic plates $\left(60 \mathrm{G} \mathrm{F}_{254}\right.$, $0.25 \mathrm{~mm}$ ) and the mobile phases used included formic acid, acetone and dichloromethane (8,5:25:85 v/v). The retention factor $(R)$ of the sample was compared with that of the reference standard. The spots were visualized under UV light at a wavelength of $365 \mathrm{~nm}$. Lyophilized samples and the RA standard were analyzed individually via infrared spectroscopy (IR, SPECTRUM ${ }^{\text {TM }}$ FT-IR/ FT-FIR 400, Perkin Elmer and Waltham, MA, USA) in the range $4000-450 \mathrm{~cm}^{-1}$. HPLC characterization was done by following method described by Candelas and Costa, ${ }^{13}$ with adaptations. A Waters e2695 instrument was used, with a 2998 pulsed am perometric detector (PAD), Knauer, Berlin. The mobile phases included $30 \%$ acetonitrile (A) and $70 \%$ water/acetonitrile/ formic acid (97.0:2.5:0.5 v/v, B). A Waters X-Terra RP-18 column was used for separation $(5 \mu \mathrm{m}, 250 \times 4.6 \mathrm{~mm}$, at $25^{\circ} \mathrm{C}$ ). The flow rate was maintained at $0.5 \mathrm{~mL} / \mathrm{min}$ and a wavelength of $329 \mathrm{~nm}$ was used for detection. Chromato graphic peaks corresponding to RA were identified by matching retention times and UV absorbance with standard.

\section{Identification of RA}

The melting point was resolved using a computerized dissolving point mechanical assembly (Microteknik, India). Spectral data from the selected extract portions acquired by means of IR were assessed as previously described. HPLC was performed utilizing a $\mathrm{C}_{18}$ column $(250 \times 4.6 \mathrm{~mm}$, $5 \mu \mathrm{m})$ and mobile phase comprised of methanol and phosphate. The sample was run along with mobile phase for $0-25$ min, methanol $40-48 \%$; and $20-45$ min., methanol $64-82 \%$. The column temperature was maintained at $40^{\circ} \mathrm{C}$, the flow rate was $1.0 \mathrm{~mL} / \mathrm{min}$ and the recognition wavelength was $338 \mathrm{~nm} .{ }^{6,13}$

\section{Acute toxicity study}

Acute oral toxicity was assessed by the Organization for Economic Cooperation and Development guidelines (OECD-423). In this study, three wistar rats weighing (180-200 g) were utilized, and were fasted overnight and provided with water. The mice received $5 \mathrm{mg} /$ $\mathrm{kg}$ of RA orally (p.o.). The administered dose was considered poisonous if mortality was observed in a 2 mice. If treatment was thought to lead to the death of an animal, at that point an experiment was repeated at the same dose to affirm poisonous quality. If no deaths were observed, a similar strategy was repeated with higher doses, for example, 50, 300 and $2000 \mathrm{mg} / \mathrm{kg}$ body weight and adverse events, including mortality or changes in behavior, body weight and toxicity were recorded (OECD-423, 2001) (Table 4). ${ }^{14}$

\section{Freund's adjuvant-induced arthritis}

Joint inflammation was induced in rats by sub-plantar infusion of $1 \mathrm{mg}$ heat killed $M$. tuberculosis (CFA) into the left paw at day 0.14 days after immunization, the rats were split into five groups ( $n=6$ per group) based on the severity of joint pain, with the aim that rats in each group demonstrated the same severity toward the start of treatment. Groups were as follows: rats in group I (vehicle-treated group) received $1 \mathrm{~mL}$ saline solution, rats in group II (negative control) received $0.1 \mathrm{~mL} \mathrm{CFA} \mathrm{and}$ no drug treatment, rats in group III were administered methotrexate $(1 \mathrm{mg} / \mathrm{kg}$, weekly intraperitoneally injection, i.p.) and rats in groups IV and $\mathrm{V}$ were orally administered 30 and $60 \mathrm{mg} / \mathrm{kg} \mathrm{RA}$, respectively, from day 14 to 35 . Paw volume was measured on days 0,7 , 14, 21, 28 and 35 using a plethysmometer. On day 36, animals were sacrificed via cervical dislocation and blood samples were collected via heart puncture. Serum was isolated via centrifugation and used to estimate levels of marker enzymes such as AST, ALT and ALP using commercially available kits. TNF- $\alpha$ levels were estimated via capture enzyme-linked immunosorbent assay (ELISA). Further more, hind paw samples were subjected to histopathological analysis. ${ }^{15-17}$ The results were expressed as changes in paw volume $(\mathrm{mL})$ according to the following formula.

Volume of edema $=$ paw volume final - paw volume intial

\section{Evaluation parameters}

i. Muscle rigidity: Muscle inflexibility and joint grip action were resolved utilizing rotarod apparatus. All rats underwent two initial instructional trainings of 
$300 \mathrm{sec}$. After the initial trials. The time each rat stayed on the rotarod was recorded. ${ }^{18}$

ii. Hypolocomotion: Locomotor action was estimated utilizing an actophotometer as indicated by the technique described by Bishnoi et al. ${ }^{19,20}$

iii. Body weight changes: The body weights of rats were recorded prior to the start of the experiment and consistently before the behavior evaluation or the last day of the trial.

\section{Biochemical measurements}

\section{i. Serum parameters (AST, ALT and ALP)}

Blood samples were collected via heart puncture on day 36 and serum was isolated via centrifugation. Enzyme levels were measured using diagnostic kits and a spectrophotometer.

ii. Hematological parameters (hemoglobin, $\mathrm{Hb}$; erythrocyte sedimentation rate, ESR)

$\mathrm{Hb}$ was measured in serum as described by Ramesh et al. ${ }^{21}$ and ESR was assessed in blood as described by Winthrobe. ${ }^{22}$

\section{Statistical analysis}

All values were expressed as means \pm standard error of the mean (SEM). Data were analyzed one way (ANOVA) followed by Dunnett's correlation tests and other data were assessed utilizing Graph Pad PRISM Version 7.

\section{RESULTS}

\section{Phytochemical profile of methanolic extracts and isolated RA}

The obtained methanolic extracts were semisolid, had light brownish masses (yield-4.76/100gm of powdered leaves) and contained alkaloids, flavonoids, glycosides, steroids, tannins and phenols (Table 1). R. officinalis L. presented the highest phenolic content $(2.17 \pm 0.58$ pyrogallol equivalent $\mathrm{L}^{-1}$ ) and the total flavonoid content was $0.96 \pm 0.84$ quercetin equivalents $\mathrm{L}^{-1}$. The isolated RA powder had a yield of $2.15 \%$.

\section{Isolation and structural identification of RA}

The melting points of the separated RA fraction were compared with those of a range of RA standards (171$\left.175^{\circ} \mathrm{C}\right)$. The $\mathrm{R}_{f}$ value of the $\mathrm{RA}$ fraction $\mathrm{RA}_{1}$ was 0.17 , identical to that of standard RA, in a mobile phase of benzene/pyridine/formic corrosive (36:9:5, BPF). The UV spectrum of the isolated RA fraction was $338 \mathrm{~nm}$. The IR range of the RA sample from $R$. officinalis demonstrated strong bands at 3351, 1632, 1498 and $1452 \mathrm{~cm}^{-1}$, suggesting the nearness of hydrogen $\mathrm{OH}$ extending, chelated carbonyl $\mathrm{C}=\mathrm{O},\left(\mathrm{C}=\mathrm{C}\right.$ at $\left.1608 \mathrm{~cm}^{-1}\right)$

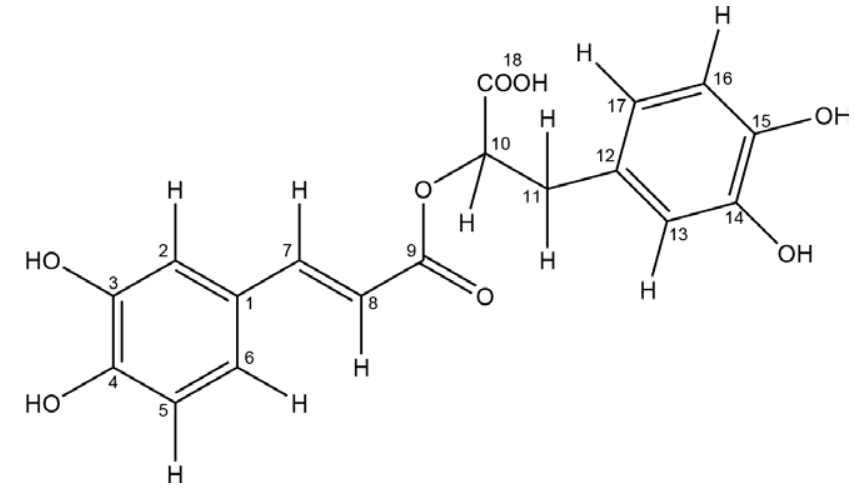

Figure 1: Structure of Rosmarinic Acid.
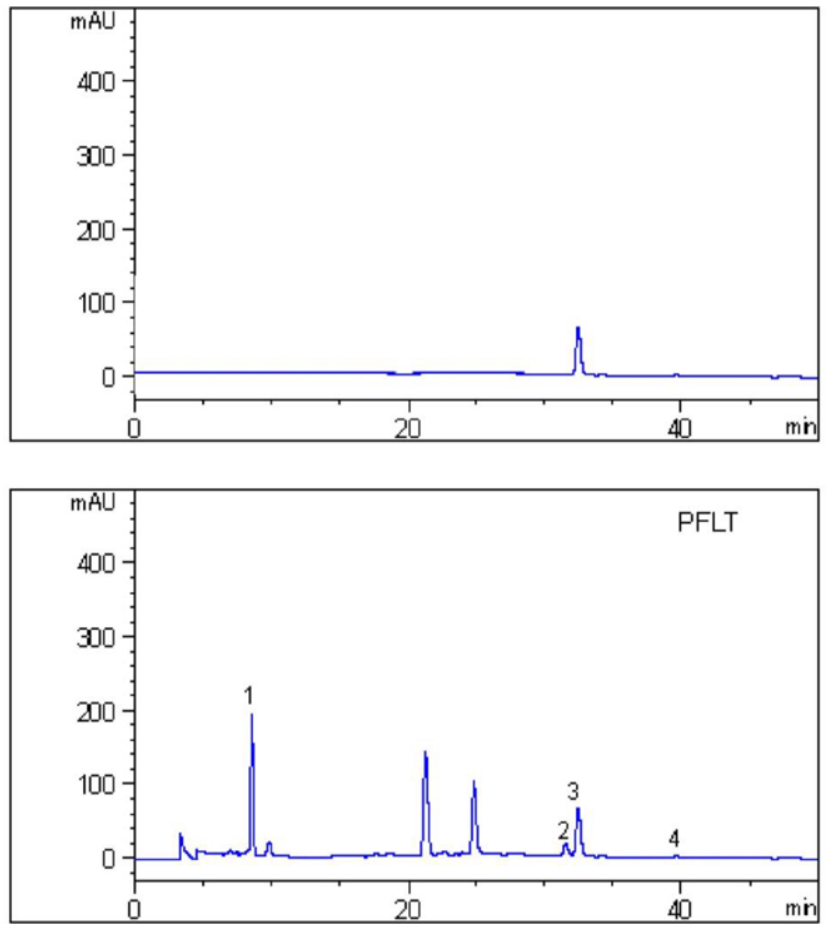

Figure 2: HPTLC chromatogram of standard rosmarinic acid (above) and HPTLC chromatogram of extract. Where marked peak (3) were matched with standard rosmarinic acid.

extending and aromatic ring functionalities (sweet-odor), as observed in standard RA (Figure 1 and 2).

\section{Effect of the methanolic extract of RA on CFA-induced arthritis in rats}

Joint inflammation in rats was assessed utilizing a plethysmograph. Paw volume, recorded as an intermediary for inflammation, was $0.3 \pm 0.08 \mathrm{~mL}$ in the vehicletreated group (I). Rats in the CFA-treated group (group II) demonstrated a non-significant change in paw volume on day 0 , which then increased each week in response to CFA treatment, compared with group I. Rats treated with methotrexate $(1 \mathrm{mg} / \mathrm{kg}$, i.p.) also demonstrated a non significant increase in paw volume compared with untreated rats on day $0(0.29 \pm 0.12 \mathrm{~mL})$, which then 


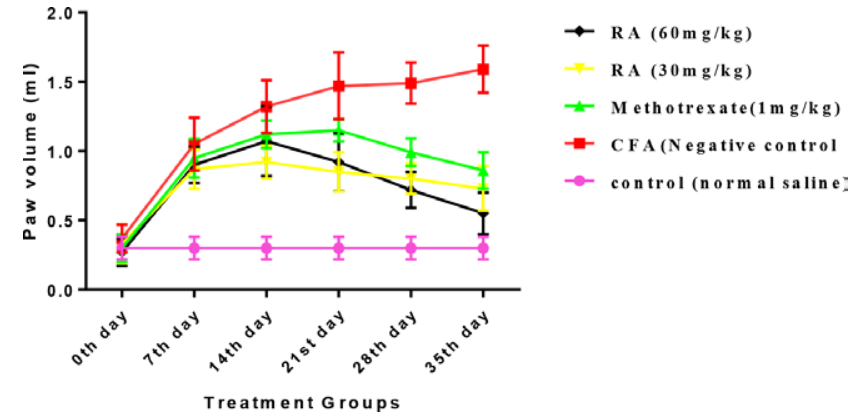

Figure 3: Effect of RA on CFA induced Arthritis in Rats.

increased $(p<0.05)$ on day 7 and after the start of treatment on day $14(p<0.01)$. There was marked reduction $(p<0.05)$ on days 21, 28 and 35 compared with the effect on ligaments in CFA-treated (group II) rats around the same time, although treatment with RA (group IV, $30 \mathrm{mg} / \mathrm{kg}$, p.o.) caused a small decrease on days 28 and 35. Treatment with $60 \mathrm{mg} / \mathrm{kg}$ (i.p.) RA caused a notable change in joint movement $(p<0.01)$ from day14 to 35 of the experiment, in contrast to that in the negative control group (group II). From the beginning of the investigation to day 35, the arthritic index was determined based on various observations and the arthritic index was determined as the total value of scores recorded for every rat (Figure 3).

\section{Effect of RA on CFA-induced muscle rigidity in rats}

Muscle rigidity was evaluated in rats using a rotarod apparatus. Weekly observations revealed that animals in the vehicle-treated control group (group I) remained on the rotarod for 120.9-122.7 seconds before falling. Animals in the CFA-treated group (group II) showed a nonsignificant difference in muscle rigidity on day 0 , which then significantly decreased $(p<0.01)$ weekly compared with that in group I. The rotarod readings, which indicated joint rigidity, decreased continuously from day 7 to 35 compared with animals in the control group. Animals treated with methotrexate $(1 \mathrm{mg} / \mathrm{kg}$, i.p., starting on day 14) showed a significant increase in muscle activity from day 21 to 35 compared with those in the CFAtreated (group II) on the same day. Treatment with RA (group IV, $30 \mathrm{mg} / \mathrm{kg}$, p.o.) significantly increased $(p<0.01)$ muscle activity from day 28 to 35 . Animals treated with $60 \mathrm{mg} / \mathrm{kg}$ (i.p.) RA showed earlier improvements in muscle activity on days 21, 28 and 35 compared with those in the negative control group (group II; Figure 4).

\section{Effect of RA on CFA-induced hypolocomotion in rats}

Locomotor action in rats was assessed utilizing an actophotometer. In the vehicle-treated control rats (I), this movement was 75-76 counts per 5 min. CFAtreated rats in group II demonstrated a non-significant

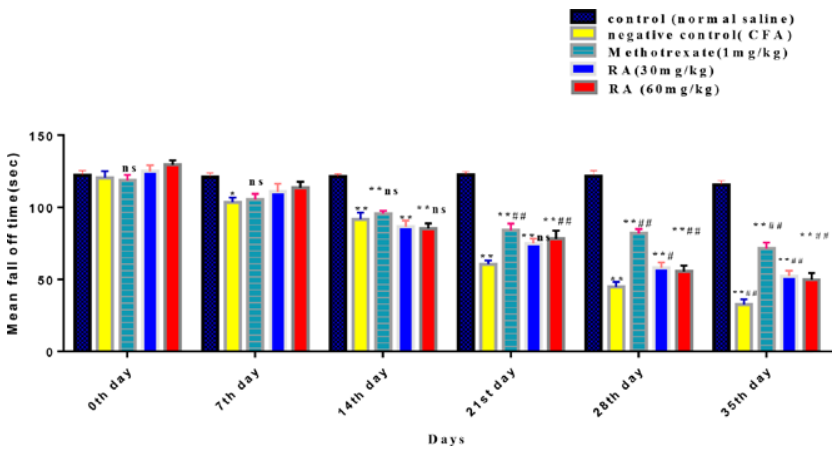

Figure 4: Effect of RA on CFA induced muscle rigidity in rats. All values are expressed as Mean \pm SEM, $(n=6)$ and a- significant difference compared to Control, ${ }^{* t *} P<0.001$,

${ }^{*} P<0.01,{ }^{*} P<0.05$, significant difference compared to CFA when ${ }^{\# \# \#} P<0.001,{ }^{\# \#} P<0.01,{ }^{\#} P<0.05$ (one-way ANOVA, followed by Dunnet test.

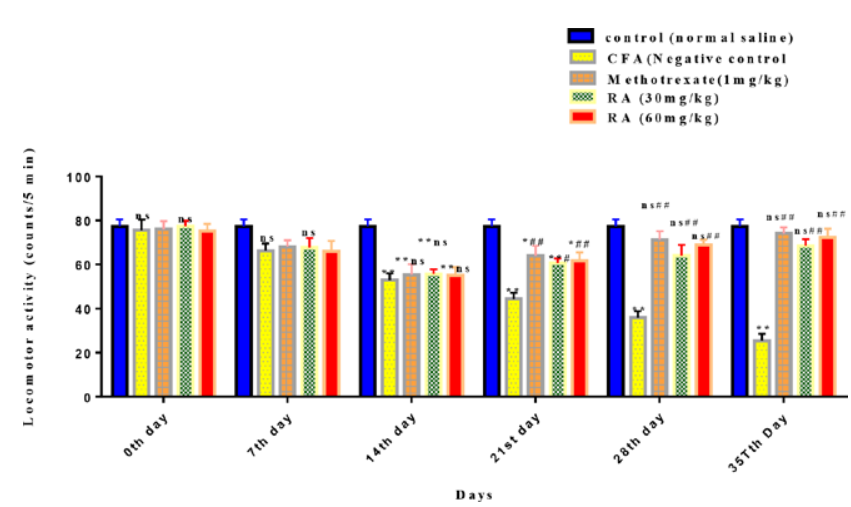

Figure 5: Effect of RA on CFA induced hypolocomotion in rat. all values are expressed as Mean $\pm \operatorname{SEM},(n=6)$ and a- significant difference compared to Control, ${ }^{, * *} P<0.001$,

${ }^{*} P<0.01,{ }^{*} P<0.05$, significant difference compared to CFA when ${ }^{\# \# \#} P<0.001,{ }^{\# \#} P<0.01,{ }^{\#} P<0.05$ (one-way ANOVA, followed by Dunnet test.

difference in movement on day $0(75.6 \pm 4.82$ counts per 5 min), which diminished altogether $(\phi<0.01)$, consistent with that in the control group. Locomotor action in group II continued to increase on day 14, The movement increased markedly on day 35 compared with the control group (group I). Rats treated with RA (60 mg/kg, i.p., group V) presented a significant $(p<0.01)$ difference in locomotor movement from days 21 to 35 compared with those in the negative control group (group II; Figure 5).

\section{Effect of RA on body weight}

Mean body weight was found increased $(p<0.01)$ in CFA-treated rats (gather II) as compared with rats in the control group (group I). Methotrexate treatment (1mg/ $\mathrm{kg}$ ) and RA treatment (30 and $60 \mathrm{mg} / \mathrm{kg}$ ) both caused a significant reduction $(\phi<0.05)$ when compared with CFA treatment (group II). Treatment with $60 \mathrm{mg} / \mathrm{kg} \mathrm{RA}$ resulted in either a small or no change in body weight compared with the control group (Group I) (Table 2). 


\begin{tabular}{|c|c|c|c|c|c|c|}
\hline \multicolumn{2}{|c|}{ Table 2: Effect of RA on Body weight changes in rats. } \\
\hline \multicolumn{2}{|c|}{ Groups } & $\begin{array}{c}\text { Control } \\
\text { (Saline) }\end{array}$ & $\begin{array}{c}\text { Negative Control } \\
\text { (CFA) }\end{array}$ & $\begin{array}{c}\text { Standard } \\
\text { (Methotrexate) }\end{array}$ & RA (30 mg/kg) & RA (60 mg/kg) \\
\hline $\begin{array}{c}\text { Mean Body } \\
\text { Weight } \\
\text { (gm) }\end{array}$ & $\begin{array}{c}\text { Before } \\
\text { (On 0 } 0^{\text {th }} \text { Day) }\end{array}$ & $121.34 \pm 1.98$ & $124.23 \pm 2.12^{* *}$ & $122.45 \pm 2.35^{* * \mathrm{~ns}}$ & $121.67 \pm 3.17^{* * \mathrm{~ns}}$ & $126.34 \pm 2.85^{* * \sharp}$ \\
\cline { 2 - 7 } & $\begin{array}{c}\text { After (On 35 } \\
\text { Day) }\end{array}$ & $125.23 \pm 0.87$ & $182.1 \pm 3.17^{* *}$ & $161.3 \pm 2.15^{* *}$ & $161.3 \pm 2.15^{* *}$ & $147.4 \pm 1.94^{* * \mathrm{~ns}}$ \\
\hline \multicolumn{2}{|c|}{$\begin{array}{c}\text { Mean difference in Body } \\
\text { weight (gm) }\end{array}$} & $3.89 \pm 1.11$ & $57.8 \pm 1.05^{* *}$ & $19.85 \pm 1.03^{* \mathrm{~ns}}$ & $39.63 \pm 1.02^{* \mathrm{~ns}}$ & $21.6 \pm 1.91^{\text {ns }}$ \\
\hline
\end{tabular}

${ }^{*} p<0.05,{ }^{* *} p<0.01,{ }^{* * *} p<0.001$ as compared to Vehicle treated control group (Group I) on the respective week.

${ }^{\#} p<0.05, " \# p<0.01, " \# \#<<0.001$ as compared to CFA treated negative control group (Group II) on the respective week NS: Non-significant.

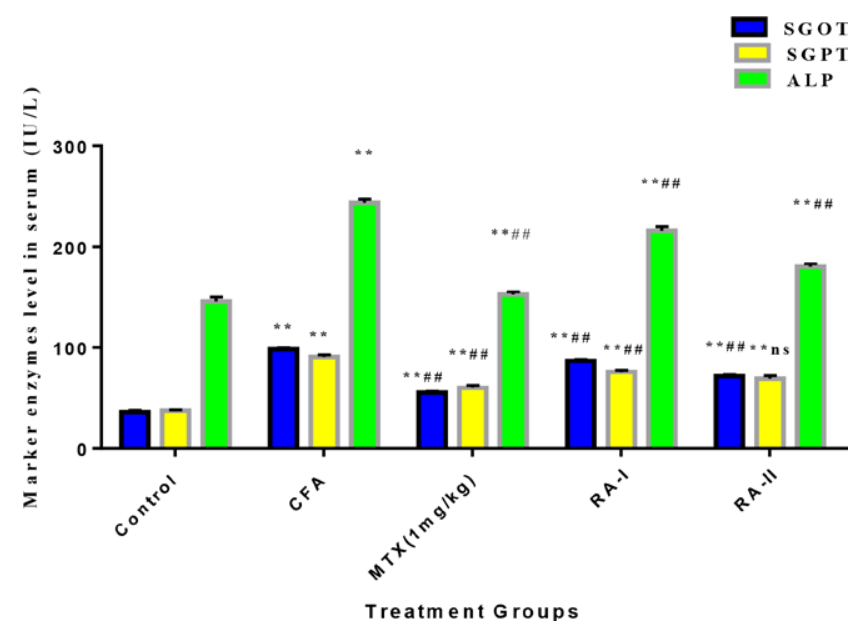

Figure 6: Effect of RA on Serum Parameters of CFA induced arthritis in rats. All values are expressed as Mean \pm SEM, $(n=6)$ and a- significant difference compared to Control, ${ }^{* * *} P<0.001,{ }^{\text {"* }} P<0.01,{ }^{*} P<0.05$, significant difference compared to CFA when ${ }^{\# \# \#} P<0.001,{ }^{\# \#} P<0.01,{ }^{\#} P<0.05$ (one-way ANOVA, followed by Dunnet test.

Effect of RA on serum parameters in rats with CFAinduced arthritis

ALT, AST, and ALP levels in blood serum from rats of the control and trial groups are shown in Figure 5. These levels were higher in rats in the CFA group (II) compared with those in the control rats. Methotrexate treated rats demonstrated a marked decrease in ALT, AST and ALP levels on day 35 compared with CFA-treated rats (group II). The increased enzyme levels diminished after treatment with RA in a dose-dependent manner compared with CFA (group II; Figure 6).

\section{Effect of RA on serum TNF- $\alpha$ levels in rats with CFA- induced arthritis}

All CFA-treated rats demonstrated increased serum levels of TNF- $\alpha$ (Table 3). RA-treated rats demonstrated a significant and dose-dependent decrease in serum TNF- $\alpha$ levels compared with the control group. Nonetheless, standard-treated rats presented an increase $(>2$-fold) in serum TNF- $\alpha$ level (Table 3).

\begin{tabular}{|c|c|c|}
\hline \multicolumn{3}{|c|}{ Table 3: Effect of RA On in rats TNF $\alpha$ level and } \\
change in Arthritic Index. \\
\hline Groups & $\begin{array}{c}\text { TNF } \alpha \\
\text { (pg/ml of serum) }\end{array}$ & $\begin{array}{c}\text { Arthritic } \\
\text { Index }\end{array}$ \\
\hline Control (Normal Saline) & $30.45 \pm 0.78$ & ------ \\
\hline CFA (Negative control) & $182.54 \pm 2.54$ & 2.80 \\
\hline $\begin{array}{c}\text { Methotrexate(1mg/kg) } \\
\text { [Standard] }\end{array}$ & $67.31 \pm 3.76^{*}$ & 0.60 \\
\hline $\mathrm{RA}(30 \mathrm{mg} / \mathrm{kg})$ & $98.7 \pm 1.09^{*}$ & 2.10 \\
\hline $\mathrm{RA}(60 \mathrm{mg} / \mathrm{kg})$ & $74.65 \pm 2.12^{*}$ & 1.60 \\
\hline
\end{tabular}

where ${ }^{*} p<0.05,{ }^{* *} p<0.01,{ }^{* * *} p<0.001$ as compared to Vehicle treated control group

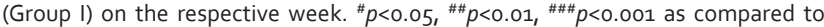
CFA treated negative control group (Group II) on the respective week, NS: Nonsignificant

\section{Effect of RA on blood parameters in rats with CFA-induced arthritis}

Hematological evaluations demonstrated an increase in ESR and reduction in hemoglobin $(\mathrm{Hb})$ content in CFA-treated rats (group II) compared with the control group (group I) rats. Rats treated with methotrexate $(1 \mathrm{mg} / \mathrm{kg})$ demonstrated notable changes in ESR and $\mathrm{Hb}$ content compared with those in the control group; however, large changes were observed $(p<0.01)$ when compared with CFA-treated (amass II) rats. RA (30mg/ $\mathrm{kg}$ ) resulted in a large change $(p<0.01)$ in ESR and $\mathrm{Hb}$ content compared with the control group and treatment with $60 \mathrm{mg} / \mathrm{kg}$ resulted in critical changes $(p<0.05)$ in ESR and $\mathrm{Hb}$ content on day 35 compared with the control and CFA-treated groups (Figure 7).

\section{Observations}

The following changes occurred in rats subjected to CFA-induced arthritis ( $0.1 \mathrm{~mL}$ CFA administration for 14 days). Changes were observed for the first 7 days before treatment was initiated on day 14. Treatment was continued until day 35 and changes were observed.

\section{Paw volume changes recorded as plethysmograph readings in $m L$}

1- In the control group, saline was administered orally and caused no significant changes in paw volume. No symptoms of rheumatoid arthritis were noted. 


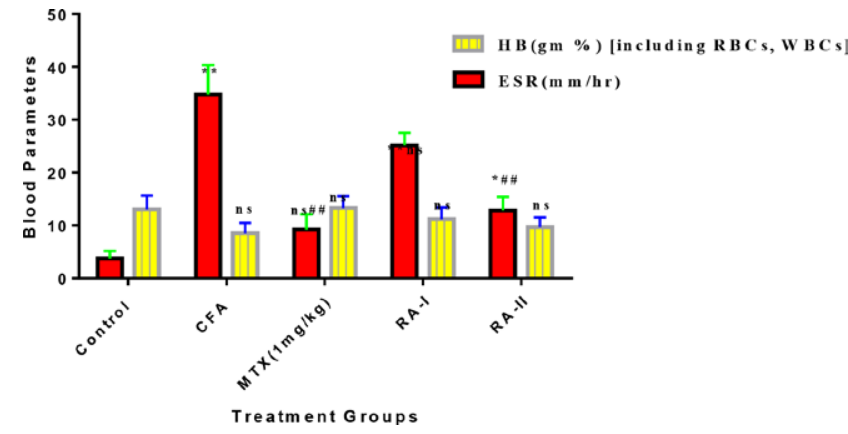

Figure 7: Effect of RA on Blood Parameters (Hb, ESR) of CFA induced arthritis in rats. All values are expressed as Mean \pm SEM, $(n=6)$ and a- significant difference compared to Control, ${ }^{* * *} P<0.001,{ }^{\text {"* }} P<0.01,{ }^{*} P<0.05$, significant difference compared to CFA when ${ }^{\# \# \# P} P<0.001,{ }^{\# \# P} P<0.01,{ }^{\# P} P<0.05$ (one-way ANOVA, followed by Dunnet test.

2- In the negative control group, arthritis induced rats showed symptom, such as the formation of nodules in the ears, tail and fore paws and resulted in highly significant increases in paw volume.

3-In the group treated with methotrexate, a potent disease-modifying antirheumatic drug (DMARD), there was a significant decrease in rheumatoid arthritis like symptoms and paw volume

4- In groups treated with the test compound, 30 and 60 $\mathrm{mg} / \mathrm{kg}$ RA were administered and a significant decrease in left hind paw volume was observed. Treatment with 60 $\mathrm{mg} / \mathrm{kg}$ RA was more effective than $30 \mathrm{mg} / \mathrm{kg} \mathrm{RA}$ and caused a significant decrease in paw volume and various other rheumatoid arthritis-like symptoms, including inflammation, nodules, and joint stiffness.

Histopathological changes Histopathological changes included cellular changes observed in the synovial membrane (Figures 8).

\section{DISCUSSION}

The results of the present study support previous findings relating to CFA-induced arthritis in rats ${ }^{23}$ and suggest a potentially significant role for RA in the treatment of rheumatoid arthritis. Adjuvant and carrageenan are two established agents used to induce arthritis and inflammation, respectively. Freund's adjuvant is more clinically relevant in the study of joint cartilage erosion, bone destruction and its remodeling. The locomotor reduction, however, might also to some extent be caused by reduced ability to move due to the pathological changes. Therefore, a complete recovery of locomotor activity cannot be expected after treatment with antinociceptive compounds. Degeneration and destruction of periosteum and bone tissue with adhesions in the joints, resembling the changes in human rheumatoid arthritis, have been demonstrated in arthritic rats within the first 4-6 weeks after inoculation. ${ }^{24}$ The presence of other alterations such as reduced weight gain, as seen in the present experiment, hyperventilation and affected pain responsiveness ${ }^{25,26}$ stress the severity of these changes and underline the similarities with conditions in human's suffering from chronic pain. It has long been known that joint stiffness is a common symptom of many rheumatic diseases.

This study also observed more stiffness/muscle rigidity in CFA treated rats in initial phase which was similar to previous studies. ${ }^{5,27}$ The rats in induced CFA-treated rats demonstrated delicate tissue swelling around lower leg joints amid the development of joint inflammation. The induction of cyclooxygenase 2 (COX-2) expressions, which occurs during the early phase of inflammation, leads to an increase in prostaglandin E2 (PGE2) production, which is associated with the selective up-regulation of microsomal prostaglandin E synthase-1 (mPGES-1); ${ }^{28}$ this was also observed in our study through changes in paw volume. The rats paw with more swelling or increased paw volume shown more cellular infillteration with presence of inflammatory mediators. The method used in this study to determine paw swelling is a simple and quick procedure to evaluate the degree of inflammation and to assess therapeutic effects. ${ }^{29,30}$ SGOT, SGPT and ALP levels provide a better indication of anti-arthritic activity, as these are reportedly increased in arthritic rats. ${ }^{31}$ The levels of these enzymes, which are considered to be

\begin{tabular}{|c|c|c|c|c|c|c|c|c|}
\hline \multirow[t]{2}{*}{ S. No } & \multirow{2}{*}{$\begin{array}{l}\text { Treatment } \\
\text { group }\end{array}$} & \multirow[t]{2}{*}{ Dose } & \multicolumn{2}{|c|}{ Weight of animal in gm } & \multirow{2}{*}{$\begin{array}{l}\text { Signs of } \\
\text { toxicity }\end{array}$} & \multirow{2}{*}{$\begin{array}{l}\text { Onset of } \\
\text { Toxicity }\end{array}$} & \multirow{2}{*}{$\begin{array}{l}\text { Reversible or } \\
\text { irreversible }\end{array}$} & \multirow[t]{2}{*}{ Duration } \\
\hline & & & Before test & After test & & & & \\
\hline 1. & RA & $2 \mathrm{~g} / \mathrm{kg}$ & 172 & 166 & $\begin{array}{c}\text { No signs of } \\
\text { toxicity }\end{array}$ & Nil & Nil & 14 days \\
\hline 2. & RA & $2 \mathrm{~g} / \mathrm{kg}$ & 169 & 165 & $\begin{array}{c}\text { No signs of } \\
\text { toxicity }\end{array}$ & Nil & Nil & 14 days \\
\hline 3. & RA & $2 \mathrm{~g} / \mathrm{kg}$ & 175 & 170 & $\begin{array}{c}\text { No signs of } \\
\text { toxicity }\end{array}$ & Nil & Nil & 14 days \\
\hline
\end{tabular}




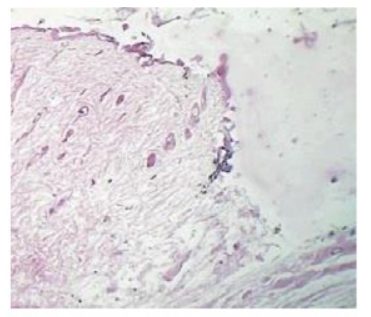

Control

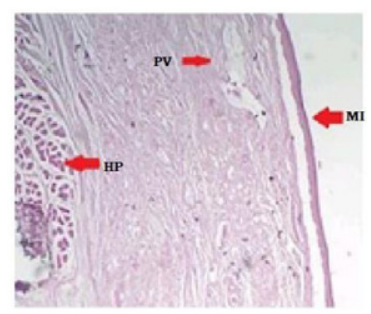

MTX

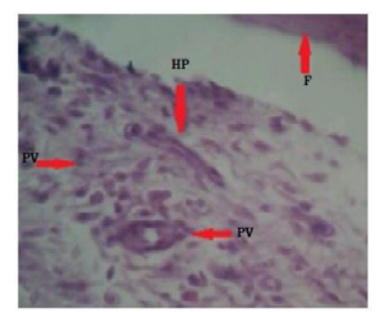

CFA

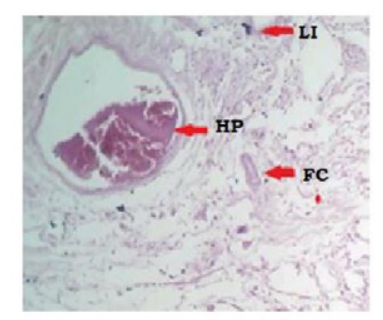

RA30

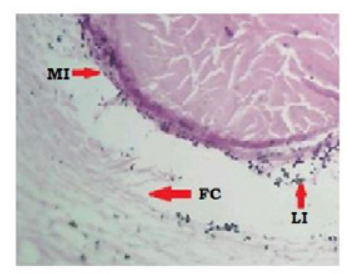

RA60

Figure 8: Figures showing histological changes in the synovial membrane of rats. Where CFA- complete fluid adjuvant induced Group-II, MTX- methotrexate treated rat's group-III, RA30-30 mg/kg,i.p, RA treated group-IV,

RA60-60mg/kg,i.p, RA treated group-V, HP-hyperplasia, PV- perivascular inflammatory infiltrates, FC- Foci of hemorrhage, MI- mononuclear inflammatory cells,

LI- Iymphoplasmacytic inflammatory infiltrates.

Control - Synovial membrane: Micro sections show tissue fragments lined by an intact benign flattened synovial epithelium. The sub synovial fibro muscular tissue is unremarkable. No crystal deposits can be seen. No inflammation or granulomas are seen. CFA-Synovial Membrane: Micro sections show tissue mild hyperplasia. A number of congested blood vessels with perivascular inflammatory infiltrate are shown. Foci of hemorrhage can be observed. MTX -Synovial Membrane: micro sections show scattered mononuclear inflammatory cells, which can be observed along with occasional blood vessels. No crystal deposits are seen. No inflammation or granulomas are seen. RA30 - Synovial membrane: micro sections show sub synovial fibro muscular tissue with an increase in lymphoplasmacytic inflammatory infiltrates. A number of congested blood vessels with perivascular inflammatory infiltrates can be seen. Foci of hemorrhage can be observed. RA60- Synovial membrane: the subsynovial fibromuscular tissue shows increased lymphoplasmacytic inflammatory infiltrates. A number of congested blood vessels with perivascular inflammatory infiltrate can be seen.

features of liver and kidney impairment in rheumatoid arthritis, decreased in RA-treated animals. ${ }^{32}$

The ESR is commonly utilized as a non-specific marker of inflammatory or threatening conditions in arthritis. ${ }^{33}$ In the present study, untreated arthritic rats showed reduced red blood cell (RBC) counts and $\mathrm{Hb}$ levels and increased ESR. These symptoms indicate an anemic condition similar to that observed in arthritic patients. ${ }^{34}$ Histopathological changes in arthritis are also useful indicators of disease sensitivity. In this study, various changes in tissue swelling were observed only in the late stages of the disease. ${ }^{35}$

RA is a complex inflammatory and autoimmune disease involving abnormalities in various cell types and factors, including macrophages, $\mathrm{T}$ cell, $\mathrm{B}$ cells, fibroblasts, chondrocytes, TNF- $\alpha$, cell adhesion molecules (CAMs), interleukins and dendritic cells. ${ }^{36}$ Our study also revealed marked differences in the levels of inflammatory mediators such as TNF- $\alpha$; reduced TNF- $\alpha$ production was observed in RA-treated animals. Herbal drugs are safer than allopathic medications and should be considered in the treatment of arthritis. Traditionally, several herbal plants have been found to be effective in preclinical models of arthritis.,

The reported activity was due to the presence of various chemical constituents in plants. The main constituents present in R. officinalis L. are 1, 8-cineole, alpha-pinene, camphor, borneol, camphene, limonene, linalool, terpineol, verbenol, apigenin, diosmetin, diosmin, oleanolic acid, and ursolic acid. Here, we reported the isolation and identification of RA in methanolic fractions from $R$. officinalis $\mathrm{L}$. and demonstrated its potential in protection against rheumatoid arthritis due to its anti-arthritic and anti-inflammatory activities.

\section{CONCLUSION}

The study concludes that RA fraction from MERO at $60 \mathrm{mg} / \mathrm{kg}$ significantly effects and controls inflammation in fluid adjuvant-induced arthritis in rat model. RA is therefore a promising plant-derived anti-arthritic compound for the treatment of inflammatory disorders.

\section{ACKNOWLEDGEMENT}

The authors want to thank all the affiliated institutes for providing the necessity research facilities.

\section{CONFLICT OF INTEREST}

The authors declare they have no conflicts of interests regarding the publication of this paper.

\section{Source of Funding}

This work is supported by Clinical Observation on Mongolian Medicine's Traditional Osteopathic Medicine and Wine Massage for Traumatic Arthritis (No 201302020). 


\section{ABBREVIATIONS}

CFA: complete Freund's adjuvant; RA: rosmarinic acid; MSD: musculoskeletal disorder; TNF: tumor necrosis factor; API: Active Pharmaceutical Ingredient; ELISA: enzyme-linked immunosorbent assay; Hb: hemoglobin; ESR: erythrocyte sedimentation rate; CAMs: cell adhesion molecules.

\section{REFERENCES}

1. Buchanan WW, Daqueker J, Hochberg MC, Silman AJ, Smolen JS, Weinblatt $\mathrm{M}$, Weisman MH History of Rheumatic Diseases, Rheumatology, $3^{\text {rd }}$ Edition. 2003;1-8.

2. Stephen JM, William FG. Pathophysiology of Disease, an Introduction to Clinical Medicine, $5^{\text {th }}$ edition. McGraw-Hill Publication. 2006;81-98.

3. Yelin E, Callahan L. The economic cost, social and psychological impact of musculoskeletal conditions. Arthritis Rheum. 1995;38(10):1351-62.

4. Lamer-Zarawska E. Biflavonoids in Juniperus L. sp (Cupressaceae). Polish J Pharmacol Pharm. 1975;27(1):81-7.

5. Bais S, Abrol N, Prashar Y, Kumari R. Modulatory effect of standardised amentoflavone isolated from Juniperus communis L. agianst Freund's adjuvant induced arthritis in rats (histopathological and $X$ Ray anaysis). Biomedicine and Pharmacotherapy. 2017;86:381-92.

6. Bai N, He K, Roller M, Lai CS, Shao X, Pan MH, et al. Flavanoids and Phenolic Compounds from Rosmarinus officinalis. J Agric Food Chem. 2010;58(9):5363-7.

7. Lee DM, Weinblatt ME. Rheumatoid arthritis. The Lancet. 2001;358:903-11.

8. Kokate CK. Practical pharmacognosy. New Delhi: Vallabh Prakashan; $5^{\text {th }}$. 2008;12-56.

9. Makkar HPS. Quantification of Tannins in Tree and Shrub Foliage: A Laboratory Manual. Kluwer Academic Publishers, Dordrecht, Netherlands. 2003;43-54.

10. Woisky RG, Salatino A. Analysis of propolis: Some parameters and procedures for chemical quality control. J Apicult Res. 1998;37(2):99-105.

11. Siddique NA, Mujeeb M, Najmi AK, Akram M. Evaluation of antioxidant activity, quantitative estimation of phenols and flavonoids in different parts of Aegle marmelos. Afr J Plant Sci. 2010;4(1):1-5.

12. Akoury E. Isolation and Structural Elucidation of Rosmarinic Acid by Nuclear Magnetic Resonance Spectroscopy. American Research Journal of Chemistry. 2017;2(1):17-23.

13. Canelas V, DaTeixeira C. Quantitative HPLC Analysis of Rosmarinic Acid in Extracts of Melissa officinalis and Spectrophotometric Measurement of their Antioxidant Activities. J Chem Educ. 2007;84(9):1502-3.

14. Ecobichnon DJ. The Basis of Toxicity Testing. $2^{\text {nd }}$ edn. New York, NY.: CRC Press. 1997;176.

15. Mythilypriya R, Shanthi P, Sachdanandam P. Therapeutic effect of Kalpamruthaa, a herbal preparation on adjuvant induced arthritis in wistar rats. J Inflammopharmacology. 2008;16(1):21-35.

16. Jaijesh P, Srinivasan KK, Bhagath KP, Sreejith G, Raju SK, Sareesh NN. Anti-arthritic potential of the plants Justicia gendarussa Burm F. J Clinics. 2009;64(4):357-62.
17. Vishal B, et al. Evaluation of Anti-Arthritis Activity of Asystasia dalzelliana Leaves. International Journal of Pharmaceutical and Biological Archives. 2012;3(2):377-82.

18. Kulkarni SK. Handbook of Experimental Pharmacology, $3^{\text {rd }}$ edition, Vallabh Prakashan, Delhi. 1999;140-43.

19. Bishnoi M, Chopra K, Kulkarni SK. Involvement of adenosinergic receptor system in an animal model tardive dyskinesia and associated behavioural. Biochem. and Neurochem. Eur J Pharmacol. 2006;552(1-3):55-66.

20. Gerhard VH. Drug discovery and evaluation, pharmacological assays, second edition. 2002;802-3.

21. Goyal RK, Patel NM. Handbook of practical anatomy and Physiology, $5^{\text {th }}$ edition Shah prakashan, Ahamdabad. 2002;18-20.

22. Lee GR. Wintrobe clinical haematology, $9^{\text {th }}$ ed., Lea and Feblger, Philedelphia. 1993;128.

23. Yende SR, Sannapuri VD, Vyawahare NS, Harle UN. Antirheumatoid activity of aqueous extract of $P$. longum on freunds adjuvant-induced arthritis in rats. Int J Pharmaceut Sci Res. 2010;1(9):129-33.

24. Baumgartner WAFWJ, Bcck A, Lorbcr CM, Pearson MW. Whitehouse: Adjuvant disease in rats: Biochemical criteria for distinguishing several phases of inflammation and arthritis. Proc Soc Exp Bid Med. 1974;145(2):625-30.

25. Colpaert FC, DenHoogen RHV. Time course ofthe ventilatory rcsponsc to adjuvant arthritis in the rat. Lije Sci. 1983;33(11):1065-73.

26. Yonehara NT, Kudo K, Iwatsubo S, Maeda K, Saito R. Inoki: A possible involvement of the central endorphin system in the autoanalgesia induced by chronic administration of Freund's adjuvant solution in rats. Puin. 1983;17(1):91-8.

27. Turnbach ME, Spraggins DS, Randich A. Spinal administration of prostaglandin $E_{2}$ or prostaglandin $F 2 \alpha$ primarily produces mechanical hyperalgesia that is mediated by nociceptive specific spinal dorsal horn neurons. Pain. 2002;97(1-2):33-45.

28. Bais S, Prashar Y. Identification and Characterization of Amentoflavone from Six Species of Juniperus Against $\mathrm{H}_{2} \mathrm{O}_{2}$ Induced Oxidative Damage in Human Erythrocytes and Leucocytes. Research Journal of Phytochemistry. 2015;9(2):41-55.

29. Singh S, Majumdar DK. Effect of fixed oils of Ocimum sanctum against experimentally induced artheritis and joint edema in laboratory animals. Int $\mathrm{J}$ Pharmacog. 1996;34(3):473-88.

30. Kataoka H, Horiyama S, Yamaki M, Oku H, et al. Anti-inflammatory and anti-allergic activities of hydroxylamine and related compounds. Biol Pharm BulL. 2002;25(11):1436-41.

31. Rainsford KD. Adjuvant polyarthritis in rats: Is this a satisfactory model for screening anti-arthritic drugs?. Agents Actions. 1988;12:452-8.

32. Combe B, Eliaou JF, Daures JP, Meyer O, Clot J, Sany J. Prognostic factors in rheumatoid arthritis. Br J Rheumatol. 1995;34:529-34.

33. Mowat AG. Hematologic abnormalities in Rheumatoid arthritis. Sem Arthr Rheum. 1971;1(3):195-219.

34. Harris ED. Rheumatoid arthritis. Pathophysiology and implications for therapy. N Eng J Med. 1990;322(18):1277-89.

35. Tran CN, Lundy SK, Fox DA. Synovial biology and T cells in rheumatoid arthritis. Pathophysiology: The Official Journal of the International Society for Pathophysiology. 2005;12(3):183-9. http://doi.org/10.1016/j. pathophys.2005.07.005

36. Shah A. Harrisions principal of internal medicine, $\left(18^{\text {th }}\right.$ ed.) united states: McGraw Hill. 2011;2738. ISBN9780071748896. 


\section{PICTORIAL ABSTRACT}

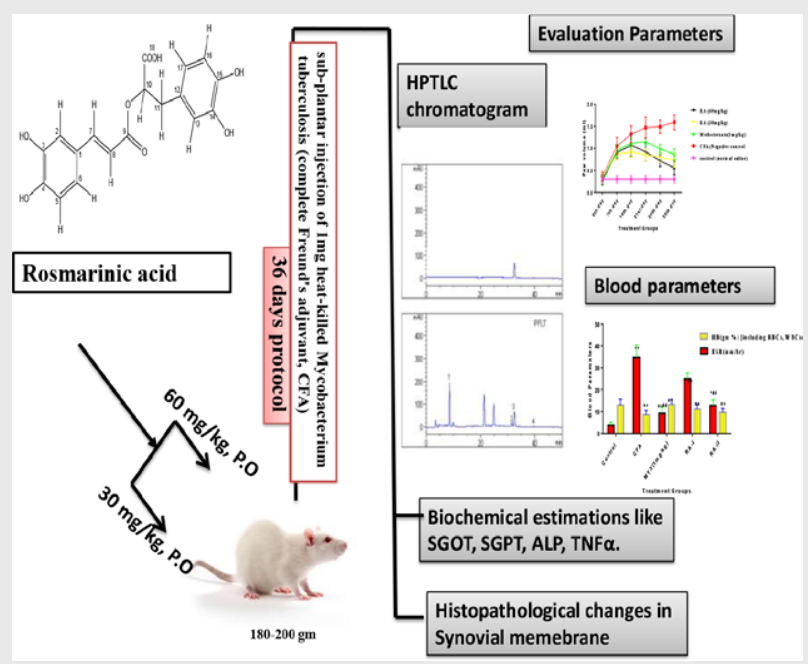

\section{SUMMARY}

Complete Freund's adjuvant, CFA treated animal showed significant change in paw volume and in release of TNF- $\alpha$. This was confirmed by histological changes in synovial membrane of rats. CFA significantly affects the both behavioral and biochemical parameters like body weight, locomotion, SGOT, SGPT, ALP, TNF $\alpha$, respectively in rats. Rosmarinic acid (RA) was isolated and confermed by different analytical techniques like TLC, HPLC and UV. Animals treated with RA from $R$. officinalis L. leaf extract showed improvement in muscle rigidity, hypolocomotion, primary and secondary lesions in arthritis induced rats and modulates the release of pro inflammatory mediators like TNF- $\alpha$ to control inflammation in joints.

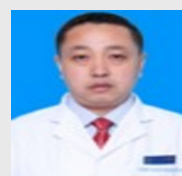

\section{About Authors}

Tianhu Wei, M.D, works in Department of Bao's orthopedic, Inner Mongolia International Mongolian Hospital. mainly research Traditional Mongolian medicine osteopathy, joint dislocations of extremities, manual reduction splint external fixation and other body fractures, soft tissue injuries, medicated wine massage treatment.

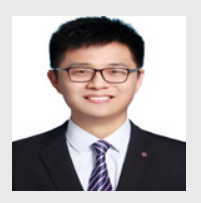

Yuan Liu, M.D, worked in Department of Emergency, The First Affiliated Hospital of Zhengzhou University, mainly research the Apoptosis in Human Nucleus, Gouty arthritis, Treatment of Osteoarthritis with bone marrow mesenchymal stem cells.

Meirong Li, M.D, works in Department of Rheumatology, XuZhou Central Hospital, mainly research the diagnosis and treatment of rheumatic immune diseases, promote the application of joint cavity irrigation to treat monoarthritis Diagnosis and treatment of rheumatic immune diseases, promote the application of joint cavity irrigation to treat monoarthritis.

Cite this article: Wei T, Liu Y, Li M. Anti-inflammatory and Anti-arthritic Activity of Rosmarinic acid Isolated from Rosmarinus officinalis in an Experimental Model of Arthritis. Indian J of Pharmaceutical Education and Research. 2021;55(2):507-16. 